\title{
Inequality, Mobility and Redistributive Taxation in a Finance-Constrained Economy
}

\author{
Ryo Arawatari ${ }^{1} \&$ Tetsuo Ono ${ }^{2}$ \\ ${ }^{1}$ Graduate School of Economics, Nagoya University, Aichi, Japan \\ ${ }^{2}$ Graduate School of Economics, Osaka University, Osaka, Japan \\ Correspondence: Ryo Arawatari, Graduate School of Economics, Nagoya University, Furo-cho, Chikusa-ku, Nagoya, \\ Aichi 464-8601, Japan.
}

Received: September 10, 2015

Accepted: September 22, $2015 \quad$ Available online: October 27, 2015

doi:10.11114/aef.v2i4.1174

URL: http://dx.doi.org/10.11114/aef.v2i4.1174

\begin{abstract}
This paper presents a simple model that displays a joint determination of income inequality and intergenerational mobility affected by redistributive taxation. The model shows that a larger redistribution improves equality and utility and enhances mobility when the poor are financially constrained, however it creates a trade-off between the rich and the poor in terms of utility when the poor are financially unconstrained. The model also shows that the size of the redistribution as well as wage inequality play key roles in explaining the cross-country differences in inequality and mobility among OECD countries.
\end{abstract}

Keywords: inequality, Gini coefficient, intergenerational mobility, redistributive taxation, financial constraints

\section{Introduction}

Income inequality and intergenerational mobility are strongly related to each other (Piketty, 2000). On one hand, greater inequality leads to underinvestment in education by the poor, thereby resulting in lower upward mobility of poor-born individuals. On the other hand, lower upward mobility implies a larger number of poor, thereby resulting in higher inequality in the economy. This mutual link implies a negative correlation between inequality and mobility. This correlation is supported by empirical evidence among OECD countries (OECD, 2006; D'Addio, 2007): Nordic countries are characterized by low inequality and high mobility while Italy, the United Kingdom and the United States are characterized by high inequality and low mobility.

Redistributive institutions (such as income redistribution and public education) may have the potential to play an important role in determining inequality and mobility (Checchi, Ichino and Rustichini, 1999; Iyigun, 1999; Hassler, Rodriguez Mora and Zeira, 2007; Ichino, Karabarbounis and Moretti, 2008). For example, income redistribution from the rich to the poor can expand the resources of the poor available for educational investment, which may in turn increase upward mobility and reduce inequality in the economy. However, income redistribution has a negative income effect on the rich, which may result in a trade-off between the rich and the poor in terms of welfare. Therefore, the following questions arise. How do redistributive institutions affect inequality, mobility and welfare? Under what conditions does redistribution improve the equality, mobility and welfare of each type of individual?

The aim of this study is to provide a simple theory of inequality, mobility and redistributive taxation that can be used to address the above-mentioned questions. For the purpose of analysis, we develop a two-period-lived overlapping-generations model that introduces endogenous intergenerational mobility via educational investment. In this framework, parents are assumed to invest in education for their children. Poor-born individuals may have a chance of becoming rich via educational investment by parents. However, poor parents would be faced with financial constraints, thereby providing their children with a lower level of educational investment compared with rich parents. To resolve this financial problem, we consider lump-sum transfers financed by taxation of the rich. This redistribution from the rich to the poor may relax the financial constraints of the poor, thereby resulting in higher mobility and lower inequality.

Under the above-mentioned framework, we find that the economy attains multiple, stable steady-state equilibria when the redistributive tax rate is set within a certain range. One is a poverty trap where all individuals are poor; the other is 
the equilibrium where some are rich who are financially unconstrained while the others are poor who are financially constrained. The multiple stable steady-state equilibria arise because of a kind of pecuniary increasing returns stemming from financial constraints (Ljungqvist, 1993; Galor and Zeira, 1993; Banerjee and Newman, 1993; Freeman, 1996; Ghatak and Jiang, 2002; Mookherjee and Ray, 2003). The economy converges to one of the steady-state equilibria depending on the initial distribution. Policymakers can prevent the economy falling into the poverty trap by controlling the redistributive tax rate.

Given the characterization of equilibria, we consider the effects of redistributive taxation on inequality, mobility and utility of each type of individual. Raising the redistributive tax rate relaxes the constraint of the poor, thereby resulting in higher mobility and lower inequality. In addition, the tax increase is beneficial from the viewpoint of utility because the poor purely benefit from a higher tax rate, whereas the rich are neutral to this increase: an increase in the tax burden of the rich is completely offset by an increase in lump-sum transfers. A further increase in tax shifts the economy to the equilibrium where both the rich and the poor are financially unconstrained. In this new equilibrium, an increase in tax results in a trade-off between the rich and the poor in terms of utility. Therefore, a tax increase is beneficial from the viewpoint of equality, mobility and utility as long as the economy stays in the equilibrium where the poor are financially constrained.

The analysis and results of this paper provide possible explanations for the following two empirical findings. First, as mentioned above, Nordic countries are characterized by high redistributive tax rates, low inequality and high mobility, while Italy, the United Kingdom and the United States are characterized by low redistributive tax rates, high inequality and low mobility. This evidence can be explained by the model prediction that a country with a higher redistributive tax rate is characterized by lower inequality and higher mobility when poor individuals are financially constrained. Therefore, income redistribution from the rich to the poor is a key to explaining the negative correlation between inequality and mobility among a sample of OECD countries. Second, when the focus is on a group of countries with low mobility and high inequality, the negative correlation between inequality and mobility does not necessarily hold: Italy, compared with the United States, displays less income inequality and less intergenerational mobility (Checchi, Ichino and Rustichini, 1999). This puzzling evidence can be explained when the difference in wage inequality is considered together with the difference in the size of the redistribution. In the current framework, a country with lower wage inequality and a higher redistributive tax rate, such as Italy, attains lower inequality and lower mobility than the United States.

The current paper relates to two strands of literature. First, some authors explain cross-country difference in inequality and mobility by showing multiple equilibria created by a kind of pecuniary increasing returns stemming from financial constraints (Owen and Weil, 1998; Mookherjee and Napel, 2007; Napel and Schneider, 2008). However, redistributive institutions are omitted from these studies. In contrast, this paper introduces redistributive taxation into a model with pecuniary increasing returns, and shows how redistribution affects the pattern of equilibria, inequality, mobility and welfare. Second, this paper focuses on income redistribution as a device for relaxing the financial constraints of the poor for educational investment. Maoz and Moav (1999) also introduce redistributive taxation into their model, but their analysis is limited to a brief illustration of figure and provides no welfare implications of redistributive taxation. In contrast, this paper provides analytically a welfare implication of redistributive taxation via inequality and mobility. Other studies on inequality and mobility focus on public education as redistributive institutions (for example, Owen and Weil, 1998; Iyigun, 1999; Checchi, Ichino and Rustichini, 1999; Davis, Zhang and Zeng, 2005; Hassler, Rodriguez Mora and Zeira, 2007; Ichino, Karabarbounis and Moretti, 2008).

The organization of this paper is as follows. Section 2 develops the model. Section 3 provides the characterization of equilibrium. Section 4 examines the effects of redistributive taxation on inequality, mobility and welfare. Section 5 provides concluding remarks.

\section{The Model}

Consider a discrete time economy where time is denoted by $t=0,1,2 \ldots$ The economy is made up of overlapping generations of individuals, each of whom has a single parent and a single child. Each generation has a unit mass. Each individual lives and works for exactly two periods, youth and old age. There is no storage technology in this economy; each individual spends on consumption and educational investment for children.

Individuals are heterogeneous at birth. Among the young born in period $t, u_{t} \in(0,1)$ are born into rich families and $u_{t} \in(0,1)$ into poor families. Parents in rich families are skilled and receive high wages, denoted by $w>0$, whereas parents in poor families are unskilled and receive low wages, normalized to zero.

Individuals have preferences for consumption in youth and old age and the education of their children. Let $e_{t}^{\text {rich }}$ and 
$e_{t}^{\text {poor }}$ denote the level of educational investment by rich and poor parents, respectively. Parents cannot borrow money for educational investment because they are deceased in the next period. The investment is financed by their own income. Parents can affect their children's prospects in life by an educational investment. In particular, we assume that the level of educational investment is equivalent to the probability of success in education. The rich-born individuals succeed in education and become skilled (rich) with probability $e_{t}^{\text {rich }}$, whereas they fail in education and become unskilled (poor) with probability $1-e_{t}^{\text {rich }}$. Similarly, the poor-born individuals succeed in education and become skilled (rich) with probability $e_{t}^{\text {poor }}$, whereas they fail in education and become unskilled (poor) with probability $1-e_{t}^{\text {poor }}$. Therefore, there is intergenerational mobility in this economy.

The proportion $\tau \in(0,1)$ of the wage $w$ of the rich is taxed by the government and the tax revenue is distributed within and across generations in a lump-sum fashion. Therefore, the after-tax-and-transfer income for the skilled (rich) is $w(1-\tau)+s_{t}$, whereas that for the unskilled (poor) is $s_{t}$, where $\tau$ is the time-invariant labor income tax rate and $s_{t}$ is the per capita lump-sum transfer in period $t$ (Note 1).

Figure 1 illustrates the timing of events and the distribution of rich and poor within and across generations. Individuals gain utility from consumption in both periods of life and from educational investment in their children. In youth, individuals use up all their income for consumption because of the assumption of no storage technology. This implies that there is no intertemporal interaction with regard to individuals' decisions. Therefore, we can focus on the decision making on consumption and education of the old individuals. The old age part of this figure will be demonstrated below.

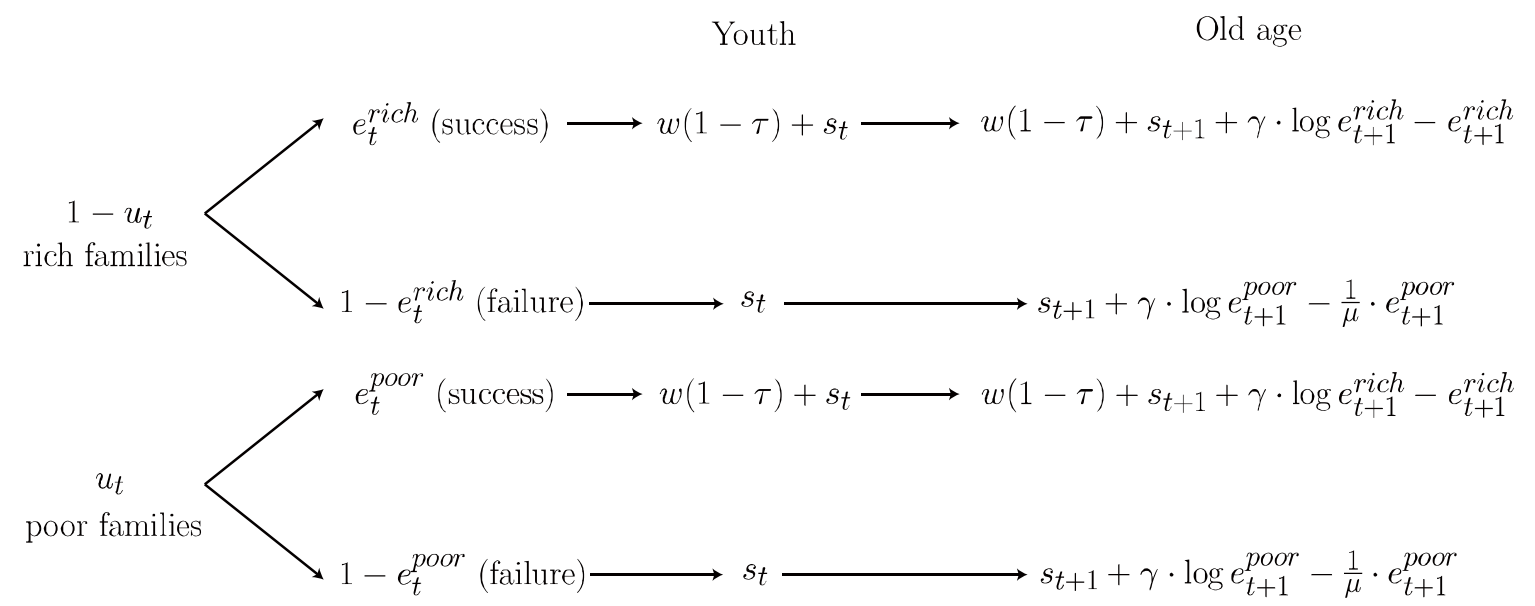

Figure 1. The timing of events and the distribution of rich and poor within and across generations.

The preferences of the rich old and the poor old over consumption and education are specified by the following quasilinear utility functions:

$$
\begin{gathered}
V_{t}^{\text {old,rich }}=\left(w(1-\tau)+s_{t}-e_{t}^{\text {rich }}\right)+\gamma \log e_{t}^{\text {rich },} \\
V_{t}^{\text {old,poor }}=\left(s_{t}-\frac{1}{\mu} \cdot e_{t}^{\text {poor }}\right)+\gamma \log e_{t}^{\text {poor }},
\end{gathered}
$$

For the rich, a part of the after-tax-and-transfer income is devoted to educational investment $e_{t}^{\text {rich }}$, and the rest $w(1-\tau)+s_{t}-e_{t}^{r i c h}$ is consumed. For the poor, the marginal cost of education is $1 / \mu>1$, which is assumed to be larger than that for the rich. The transfer minus the cost of education, $\mathrm{s}_{\mathrm{t}}-e_{t}^{\text {poor }} / \mu$, is consumed. The term $\gamma \log e_{t}^{i}(i=$ rich,poor $)$ indicates the utility of educational investment where the parameter $\gamma$ represents the degree of educational concern. We impose the following assumption with regard to the parameters $\gamma$ and $\mu$. (Note 2)

Assumption 1. $\gamma \in(0,1)$ and $\mu \in(0,1)$.

The assumption of $\gamma \in(0,1)$ ensures that the probability of success $e_{t}^{i}(i=$ rich,poor $)$ is set within the range $(0,1)$. The assumption of $\mu \in(0,1)$ implies that the marginal cost of educational investment is higher for the poor old than 
the rich old. This assumption implies that poor-born individuals must pay more costs than the rich-born individuals to obtain a certain level of education. In other words, rich-born individuals have an advantage over poor-born individuals in being educated (Becker \& Tomes, 1979; Solon, 2004; Blumkin \& Sadka, 2005; Hassler, Rodriguez Mora \& Zeira, 2007). For example, rich agents may have a home environment more suitable for education, along with better knowledge of things naturally provided to their children.

The rich old maximize their utility $V_{t}^{\text {old,rich }}$ with respect to $e_{t}^{\text {rich }}$ subject to the financial constraint $w(1-\tau)+s_{t} \geq$ $e_{t}^{\text {rich }}$; the poor old maximize their utility $V_{t}^{\text {old,poor }}$ with respect to $e_{t}^{\text {poor }}$ subject to the financial constraint $s_{t} \geq$ $e_{t}^{\text {poor }} / \mu$. Solving these problems leads to the probabilities of success for the rich-born and the poor-born individuals, given by, respectively:

$$
\begin{gathered}
e_{t}^{r i c h}=\left\{\begin{array}{ll}
\gamma & \text { if } \gamma \leq w(1-\tau)+s_{t} \\
w(1-\tau)+s_{t} & \text { if } \gamma>w(1-\tau)+s_{t}
\end{array},\right. \\
e_{t}^{\text {poor }}= \begin{cases}\gamma \mu & \text { if } \gamma \leq s_{t} \\
\mu s_{t} & \text { if } \gamma>s_{t}\end{cases}
\end{gathered}
$$

From assumption $1, e_{t}^{\text {rich }} \in(0,1)$ and $e_{t}^{\text {poor }} \in(0,1)$ are ensured.

Eqs. (3) and (4) show that the probabilities of success depend on whether the old are financially constrained or not. When the after-tax-and-transfer income of the rich is above the critical level such that $\gamma \leq w(1-\tau)+s_{t}$, the rich old can realize their preferred level of investment $e_{t}^{r i c h}=\gamma$. The probability of success is independent of the redistributive tax. In contrast, when the after-tax-and-transfer income is below the critical level $\gamma$, the rich old are financially constrained, consume nothing and invest all their income into education. In this case, the probability of success is dependent on the redistributive tax. A similar argument holds for the poor old, but the after-tax-and-transfer income is given by $s_{t}$ which is lower than that of the rich old. In other words, the poor old are more likely to be financially constrained compared with the rich old. Figure 2 illustrates the relationship between probabilities of success and after-tax-and-transfer income for the rich and the poor old.

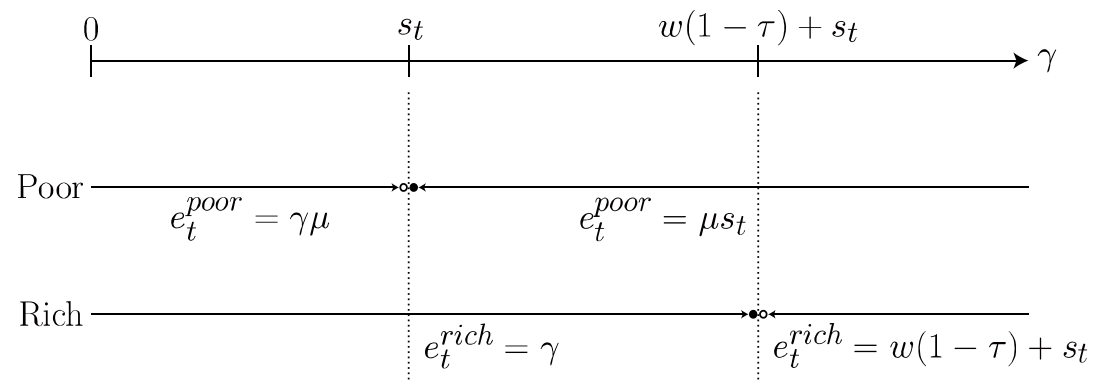

Figure 2. The probability of success for the rich and the poor.

In each period, all skilled workers are equally taxed and total tax revenue is equally divided within and across generations. Thus, the government budget constraint is:

$$
2 s_{t}=\left[\left(1-u_{t}\right) \min \left\{\gamma, w(1-\tau)+s_{t}\right\}+u_{t} \min \left\{\gamma \mu, \mu s_{t}\right\}\right] w \tau+\left(1-u_{t}\right) w \tau
$$

The left-hand side shows the total amount of redistribution. The right-hand side shows the tax revenue from the rich. The first term on the right-hand side is the tax revenue from the rich (skilled) young, and the second term on the right-hand side is the tax revenue from the rich (skilled) old.

Individuals with the same family background choose the same educational investment, implying that the proportion of the poor old in the beginning of period $t+1, u_{t+1}$ is given by:

$$
u_{t+1}=\left(1-u_{t}\right)\left(1-e_{t}^{r i c h}\right)+u_{t}\left(1-e_{t}^{\text {poor }}\right) .
$$

The first term on the right-hand side is the number of unsuccessful individuals who are born into rich families, and the second term is the number of unsuccessful individuals who are born into poor families. This equation plays a key role for the analysis of dynamic motion of inequality and mobility.

\section{Equilibrium analysis}


This section investigates the dynamic motion of the distribution of the poor. For this purpose, we first define an equilibrium, as follows.

Definition 1. An equilibrium is a sequence $\left\{u_{t}\right\}_{t=0}^{\infty}$ with the initial condition $u_{0} \in(0,1)$ and the time invariant tax rate $\tau \in[0,1]$ such that: (a) the educational investments by the rich old and the poor old are given by Eqs. (3) and (4), respectively; (b) the government budget constraint is balanced every period such that Eq. (5) is satisfied; and (c) given $u_{0} \in(0,1)$ the distribution of the poor $u_{t}$ follows Eq. (6).

As demonstrated in Figure 2, there are three cases to consider: (i) the case where both rich and poor individuals are financially unconstrained; (ii) the case where only the poor are financially constrained; and (iii) the case where both rich and poor individuals are financially constrained. For each case, we derive the condition for the existence of a steady state where an equilibrium sequence of $u_{t}$ is stationary over time. Then, we present a dynamic characterization of the equilibrium path and derive the stability condition of each steady state.

\subsection{The case where both the rich and the poor are financially unconstrained}

The rich and the poor are financially unconstrained if $\gamma \leq s_{t}$ (see Figure 2). From Eqs. (3) and (4), the probabilities of success for the rich-born and poor-born individuals are given by, respectively:

$$
e_{t}^{\text {rich }}=\gamma ; \quad e_{t}^{\text {poor }}=\gamma \mu \text {. }
$$

The probability of success for the poor-born individuals is lower than that for the rich-born individuals because the cost of educational investment is higher for the poor-born individuals.

The government budget constraint Eq. (5) is now given by:

$$
s_{t}=\frac{1}{2}\left[(1+\gamma)-\{1+\gamma(1-\mu)\} u_{t}\right] w \tau .
$$

Given this size of the redistribution, the condition $\gamma \leq s_{t}$ is rewritten as:

$$
\gamma \leq s_{t} \Leftrightarrow u_{t} \leq u_{L}(\tau) \equiv \frac{(1+\gamma) w \tau-2 \gamma}{\{1+\gamma(1-\mu)\} w \tau} .
$$

When the number of poor $u_{t}$ satisfies Eq. (7), the motion of $u_{t}$ is given by:

$$
u_{t+1}=\phi_{1}\left(u_{t}\right) \equiv(1-\gamma)+\gamma(1-\mu) u_{t} \text { if } u_{t} \leq u_{L}(\tau),
$$

with the following properties:

$$
\phi_{1}(0)=1-\gamma, \phi_{1}(1)=1-\gamma \mu, \phi_{1}^{\prime}(\cdot)=\gamma(1-\mu), \phi_{1}^{\prime \prime}(\cdot)=0 .
$$

Panel (a) of Figure 3 illustrates the graph of $u_{t+1}=\phi_{1}\left(u_{t}\right)$. 

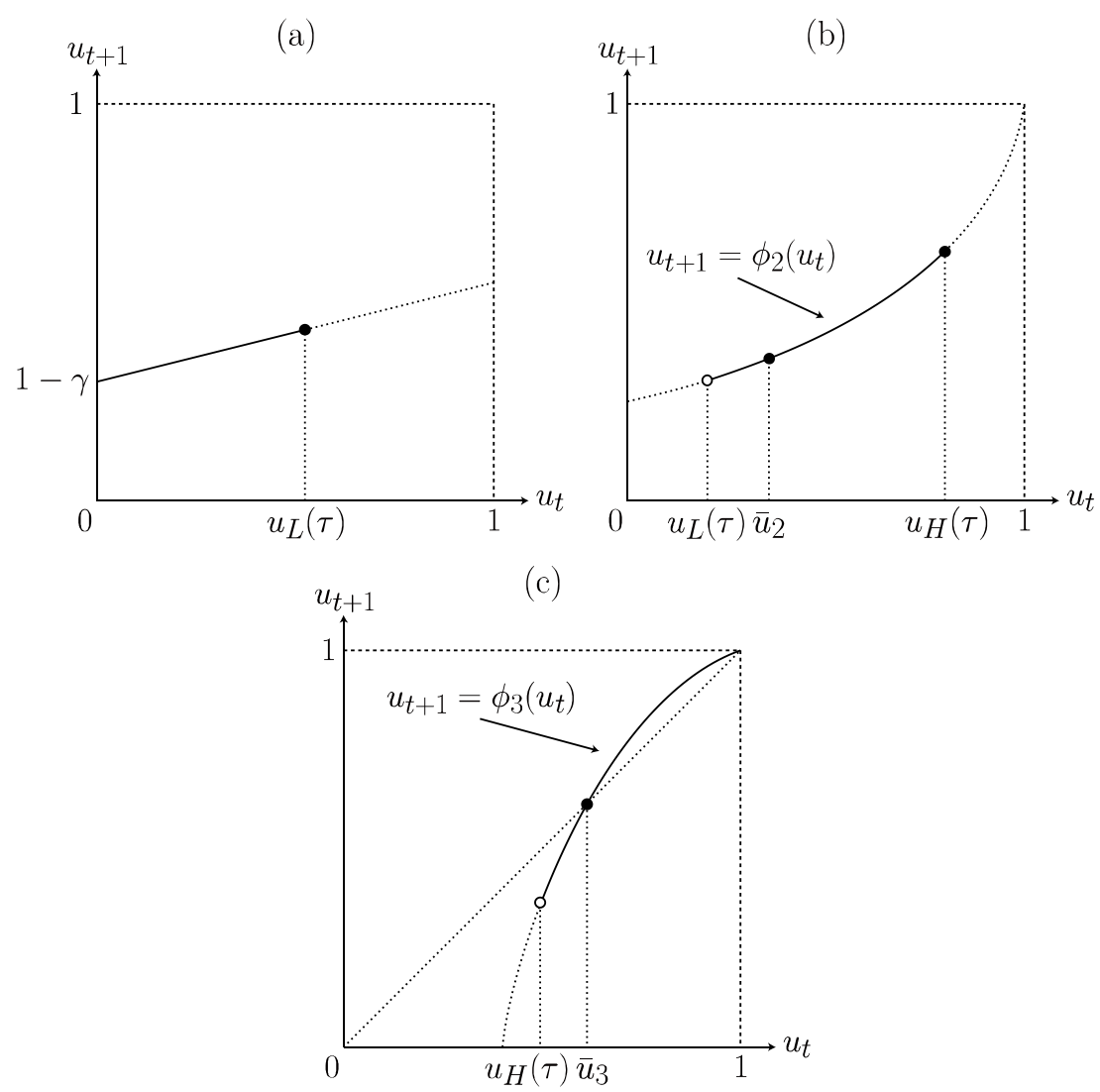

Figure 3. Dynamic motion of the distribution of the poor.

Description: Panel (a) illustrate the case of $(1-\gamma(1-\mu)) / \mu w \leq \tau$. Panel (b) illustrate the case of $(1-\gamma) \mu+\gamma \leq w$ and $\tau \in((1-\gamma) / \mu w,(1-\gamma(1-\mu) / \mu w)$. Panel (c) illustrates the case of $(w-1) /(1-\mu) w \leq \tau$ and $(1-\gamma) / \mu+$ $\gamma<w$.

We denote the steady-state level of $u$ satisfying $u_{t+1}=\phi_{1}\left(u_{t}\right)$ by $\bar{u}_{1}$ and the corresponding size of the transfer by $\bar{s}_{1}$. The following lemma establishes the condition for the existence of the steady state with $u=\bar{u}_{1}$.

Lemma 1. There exists a stable steady-state equilibrium where both the rich and the poor are financially unconstrained if:

$$
\frac{1-\gamma(1-\mu)}{\mu w} \leq \tau
$$

The number of poor and the size of the transfer are given by, respectively:

$$
\bar{u}_{1} \equiv \frac{1-\gamma}{1-\gamma(1-\mu)} \in(0,1) ; \quad \bar{s}_{1} \equiv \frac{\gamma \mu}{1-\gamma(1-\mu)} w \tau .
$$

Proof. There exists a steady-state level of $u$ satisfying $u_{t+1}=\phi_{1}\left(u_{t}\right)$ if $\bar{u}_{1} \leq u_{L}(\tau)$. This condition is rewritten as Eq. (9). Because $\phi_{1}^{\prime}(\cdot)=\gamma(1-\mu) \in(0,1)$ for all $u_{t} \in(0,1)$, the steady-state equilibrium with $u=\bar{u}_{1}$ is stable. The level of $\bar{u}_{1}$ is calculated by setting $u_{t}=u_{t+1}=\bar{u}_{1}$ in Eq. (8). The level of $\bar{s}_{1}$ is calculated by substituting $u=\bar{u}_{1}$ into the government budget constraint.

Q.E.D.

The condition Eq. (9) requires that the redistributive tax rate should be higher than or equal to the critical rate $\{1-\gamma(1-\mu)\} / \mu w$. This requirement ensures that the old receive a large enough transfer to finance educational investment. The condition Eq. (9) also requires that the wage rate of the skilled, $w$, should be higher than $(1-\gamma) / \mu+$ $\gamma$ (see Figure 4). Otherwise, the critical tax rate $\{1-\gamma(1-\mu)\} / \mu w$ becomes greater than one, implying that there is no tax rate $\tau \in(0,1)$ satisfying condition Eq. (9). 


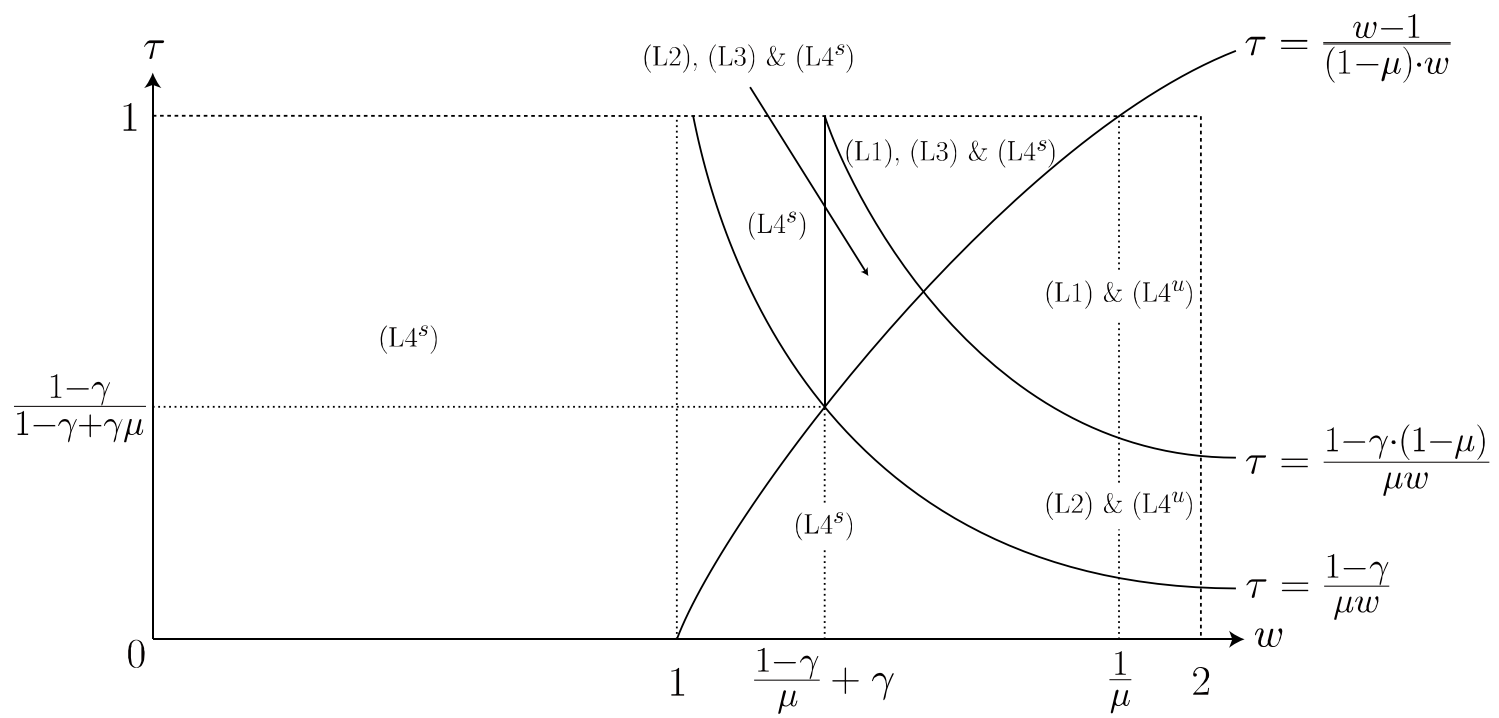

Figure 4. Existence and stability of steady-state equilibria.

The area marked by (L1) in Figure 4 indicates the set of parameters $(w, \tau)$ satisfying the condition Eq. (9).

3.2 The case where only the poor are financially constrained

We next consider the case where the rich are financially unconstrained whereas the poor are constrained. From Figure 2, this case holds if $s_{t}<\gamma \leq w(1-\tau)+s_{t}$. From Eqs. (3) and (4), the probabilities of success for the rich-born and poor-born individuals are given by, respectively:

$$
e_{t}^{\text {rich }}=\gamma ; \quad e_{t}^{\text {poor }}=\mu s_{t} .
$$

The probability of success for the rich-born individuals is independent of redistribution and is given by $\gamma$. In contrast, the probability of success for the poor-born individuals depends on the size of the redistribution because the poor are financially constrained under the condition $s_{t}<\gamma \leq w(1-\tau)+s_{t}$.

The government budget constraint Eq. (5) is now given by $2 s_{t}=\left[\left(1-u_{t}\right) \gamma+u_{t} \mu s_{t}\right] w \tau+\left(1-u_{t}\right) w \tau$, that is:

$$
s_{t}=\frac{\left(1-u_{t}\right)(1+\gamma) w \tau}{2-u_{t} \mu w \tau} \text {. }
$$

We impose the following assumption to ensure $s_{t}>0$.

Assumption 2. $w \in(0,2]$.

Given the above-mentioned size of the redistribution, the conditions $s_{t}<\gamma$ and $\gamma \leq w(1-\tau)+s_{t}$ are rewritten as follows:

$$
\begin{gathered}
s_{t}<\gamma \Leftrightarrow u_{t}>u_{L}(\tau) \equiv \frac{(1+\gamma) w \tau-2 \gamma}{\{1+\gamma(1-\mu)\} w \tau^{\prime}} \\
\gamma \leq w(1-\tau)+s_{t} \Leftrightarrow u_{t}<u_{H}(\tau) \equiv \frac{2(w-\gamma)-(1-\gamma) w \tau}{[1+\gamma(1-\mu)+\mu w(1-\tau)] w \tau} .
\end{gathered}
$$

When the number of poor $u_{t}$ satisfies Eqs. (10) and (11), the motion of $u_{t}$ is given by:

$$
u_{t+1}=\phi_{2}\left(u_{t}\right) \text { if } u_{L}(\tau)<u_{t} \leq u_{H}(\tau),
$$

Where

$$
\phi_{2}\left(u_{t}\right) \equiv\left(1-u_{t}\right)(1-\gamma)+u_{t}\left\{1-\mu \frac{\left(1-u_{t}\right)(1+\gamma) w \tau}{2-u_{t} \mu w \tau}\right\}
$$

with the following properties:

$$
\phi_{2}^{\prime}\left(u_{t}\right)=-1+\frac{2(1+\gamma)(2-\mu w \tau)}{\left(2-u_{t} \mu w \tau\right)^{2}}, \quad \phi_{2}^{\prime \prime}\left(u_{t}\right)>0
$$




$$
\phi_{2}(0)=1-\gamma, \phi_{2}(1)=1, \phi_{2}\left(u_{L}(\tau)\right)=\phi_{1}\left(u_{L}(\tau)\right) .
$$

Panel (b) of Figure 3 illustrates the graph of $u_{t+1}=\phi_{2}\left(u_{t}\right)$.

We denote the steady-state level of $u$ satisfying $u_{t+1}=\phi_{2}\left(u_{t}\right)$ by $\bar{u}_{2}$ and the corresponding size of the transfer by $\bar{s}_{2}$. The following lemma establishes the condition for the existence of the steady state with $u=\bar{u}_{2}$.

Lemma 2. There exists a stable steady-state equilibrium where only the poor are financially constrained if:

$$
\frac{1-\gamma}{\mu}+\gamma \leq w \text { and } \tau \in\left(\frac{1-\gamma}{\mu w}, \frac{1-\gamma(1-\mu)}{\mu w}\right) .
$$

The number of poor and the size of the transfer are given by, respectively:

$$
\bar{u}_{2} \equiv \frac{1-\gamma}{\mu w \tau} ; \quad \bar{s}_{2} \equiv w \tau-\frac{1-\gamma}{\mu} .
$$

Proof. There exists a steady-state level of $u$ satisfying $u_{t+1}=\phi_{2}\left(u_{t}\right)$ if $u_{L}(\tau)<\bar{u}_{2}$ and $\bar{u}_{2} \leq u_{H}(\tau)$. These inequality conditions are rewritten as:

$$
\tau<\frac{1-\gamma(1-\mu)}{\mu w} \text { and } \frac{1-\gamma}{\mu}+\gamma \leq w .
$$

With the condition $\bar{u}_{2}<1 \Leftrightarrow(1-\gamma) / \mu w<\tau$, we obtain Eq. (13).

As illustrated in Panel (b) of Figure 3, given the properties of $\phi_{2}{ }^{\prime \prime}\left(u_{t}\right)>0$ and $\phi_{2}(1)=1$, the graph of $u_{t+1}=$ $\phi_{2}\left(u_{t}\right)$ crosses the $u_{t+1}=u_{t}$ line from above at $u_{t}=\bar{u}_{2}$, implying that the steady-state equilibrium with $u_{t}=\bar{u}_{2}$ is stable. The level of $\bar{u}_{2}$ is calculated by setting $u_{t}=u_{t+1}=\bar{u}_{2}$ in Eq. (12). The level of $\bar{s}_{2}$ is calculated by substituting $u=\bar{u}_{2}$ into the government budget constraint.

Q.E.D.

The area marked by (L2) in Figure 4 indicates the set of parameters $(w, \tau)$ satisfying the condition Eq. (13). The condition requires that the wage of the skilled should be higher than $(1-\gamma) / \mu+\gamma$. Similar to the argument in Subsection 3.1, this requirement ensures that there is a tax rate $\tau \in(0,1)$ that satisfies the condition Eq. (13). In addition, the condition Eq. (13) requires that, given the wage rate, the redistributive tax rate should be higher than $(1-\gamma) / \mu \mathrm{w}$ but lower than $\{1-\gamma(1-\mu)\} / \mu \mathrm{w}$. When the distributive tax rate is below the critical rate $(1-\gamma) / \mu w$, the size of the redistribution is small; the skilled individuals cannot leave a part of their endowments for their consumption. In contrast, when the distributive tax rate is above the critical rate $\{1-\gamma(1-\mu)\} / \mu w$, the size of the redistribution is large; the poor can finance educational investment and leave a part of their endowments for their consumption. Therefore, the condition in Eq. (13) requires that the distributive tax rate should be set within the range $((1-\gamma) / \mu w,\{1-\gamma(1-\mu)\} / \mu w)$ for the existence of the steady state where only the poor are financially constrained.

\subsection{The case where both the rich and the poor are financially constrained}

Finally, we consider the case where the rich and the poor are financially constrained. This case holds if $w(1-\tau)+$ $s_{t}<\gamma$ (see Figure 2). From Eqs. (3) and (4), the probabilities of success for the rich-born and poor-born individuals are given by, respectively:

$$
e_{t}^{\text {rich }}=w(1-\tau)+s_{t} ; \quad e_{t}^{\text {poor }}=s_{t} .
$$

The probabilities of success for the rich-born and the poor-born individuals depend on the size of the redistribution because both types of the old are financially constrained under the condition $w(1-\tau)+s_{t}<\gamma$.

The government budget constraint is now given by $2 s_{t}=\left[\left(1-u_{t}\right)\left\{w(1-\tau)+s_{t}\right\}+u_{t} \mu s_{t}\right] w \tau+\left(1-u_{t}\right) w \tau$, which is rewritten as:

$$
s_{t}=\frac{\left(1-u_{t}\right)\{w(1-\tau)+1\} w \tau}{2-\left\{\left(1-u_{t}\right)+u_{t} \mu\right\} w \tau}
$$

Given this size of the redistribution, we can rewrite the condition $w(1-\tau)+s_{t}<\gamma$ as follows:

$$
w(1-\tau)+s_{t}<\gamma \Leftrightarrow u_{H}(\tau)<u_{t} .
$$

When the number of poor $u_{t}$ satisfies Eq. (14), the motion of $u_{t}$ is given by: 


$$
u_{t+1}=\phi_{3}\left(u_{t}\right) \text { if } u_{H}(\tau)<u_{t}
$$

where

$$
\phi_{3}\left(u_{t}\right) \equiv\left(1-u_{t}\right)(1-w(1-\tau))+u_{t}-\left[\left(1-u_{t}\right)+\mu u_{t}\right] \frac{\left(1-u_{t}\right)\{w(1-\tau)+1\} w \tau}{2-\left\{\left(1-u_{t}\right)+u_{t} \mu\right\} w \tau}
$$

with the following properties:

$$
\phi_{3}^{\prime}(\cdot)>0, \quad \phi_{3}^{\prime \prime}(\cdot)<0, \quad \phi_{3}(0)=\frac{2(1-w)}{2-w \tau}, \quad \phi_{3}(1)=1 .
$$

Panel (c) of Figure 3 illustrates the graph of $u_{t+1}=\phi_{3}\left(u_{t}\right)$.

We denote the steady-state level of $u$ satisfying $u_{t+1}=\phi_{3}\left(u_{t}\right)$ by $\bar{u}_{3}$ and the corresponding size of the transfer by $\bar{s}_{3}$. The following lemma establishes the condition for the existence of the steady state with $u=\bar{u}_{3}$.

Lemma 3. There exists an unstable steady-state equilibrium where both the rich and the poor are financially constrained if:

$$
\frac{w-1}{(1-\mu) w} \leq \tau \text { and } \frac{1-\gamma}{\mu}+\gamma<w .
$$

The number of poor and the size of the transfer are given by, respectively:

$$
\bar{u}_{3} \equiv \frac{w-1}{(1-\mu) w \tau} ; \quad \bar{s}_{3} \equiv \frac{(1-\mu) w \tau-(w-1)}{1-\mu} .
$$

Proof. There exists a steady-state level of $u$ satisfying $u_{t+1}=\phi_{3}(\tau)$ if $u_{-} H(\tau)<\bar{u}_{3} \Leftrightarrow(1-\gamma) / \mu+\gamma<w$. With the condition of $\left.\bar{u}_{3}<1 \Leftrightarrow(w-1)\right) /(1-\mu) w<\tau$, we obtain Eq. (16).

As illustrated in Panel (c) of Figure 3, given the properties of $\phi_{3}^{\prime \prime}(\cdot)<0$ and $\phi_{3}(1)=1$, the graph of $u_{t+1}=\phi_{3}\left(u_{t}\right)$ crosses the $u_{t+1}=u_{t}$ line from below at $u_{t}=\bar{u}_{3}$, implying that the steady-state equilibrium with $\mathrm{u}_{\mathrm{t}}=\bar{u}_{3}$ is unstable. The level of $\bar{u}_{3}$ is calculated by setting $u_{t}=u_{t+1}=\bar{u}_{3}$ in Eq. (15). The level of $\bar{s}_{3}$ is calculated by substituting $u=\bar{u}_{3}$ into the government budget constraint.

Q.E.D.

The area marked by (L3) in Figure 4 illustrates the set of parameters $(w, \tau)$ satisfying the condition Eq. (16). The condition requires that the wage of the skilled should be higher than $(1-\gamma) / \mu+\gamma$, ensuring the existence of a tax rate $\tau \in(0,1)$ satisfying condition Eq. (16). In addition, the condition Eq. (16) requires that the redistributive tax rate should be higher than $(w-1) /(1-\mu) w$.

To understand the requirement for the tax rate, recall the probability of success for the rich-born individuals, $e_{t}^{\text {rich }}=$ $w(1-\tau)+s_{t}$. A higher redistributive tax has two opposing effects on the probability of success. One is a negative effect via the after-tax income $w(1-\tau)$, and the other is a positive effect via redistribution $s_{t}$. Because the size of the redistribution $s_{t}$ depends positively on the number of rich old, the positive effect via redistribution is greater than the negative effect via the after-tax income when the number of poor at the beginning of a period, $u_{t}$, is smaller than some critical level. In this case, there is a financially unconstrained equilibrium as demonstrated in Proposition 1. In contrast, when the number of poor old is larger than some critical level, the positive effect via redistribution is less than the negative effect via the after-tax income. In this case, there is an equilibrium where both the rich and the poor are financially constrained. The result implies that the distribution of the poor at the beginning of a period is crucial for the determination of the probability of success and the distribution of the poor in the next period.

Apart from the steady-state equilibrium demonstrated in Lemma 3, there is another steady-state equilibrium where all individuals are financially constrained. This is the equilibrium with $u=1$ where all individuals are poor and no redistribution occurs in equilibrium. We call this state the poverty trap. The following lemma shows the condition for the existence and (in)stability of the poverty trap.

Lemma 4. There exists a steady-state equilibrium with $u=1$ (i.e., the poverty trap) for any $w \in[0,1]$ and $\tau \in[0,1]$. This equilibrium is stable if $\tau<(1-\gamma) / \mu w$ or $\tau>(w-1) / w(1-\mu)$; it is unstable if $\tau \in[(1-\gamma) / \mu w,(w-1) / w(1-\mu)]$.

Proof. Given that the function $\phi_{i}(\cdot)(i=1,2,3)$ satisfies $\phi_{1}(1)=1-\gamma \mu, \phi_{2}(1)=1$, and $\phi_{3}(1)=1$, there exists a steady state with $u=1$ if $\phi_{2}(1)=1$ or $\phi_{3}(1)=1$ is feasible; that is, if $u_{L}(\tau)<1 \Leftrightarrow \mu w \tau<2$. This condition always holds under assumptions 1 and 2 .

The steady-state equilibrium with $u=1$ is stable if the slope of $\phi_{i}(\cdot)(i=2,3)$ is less than one at $u=1$; that is, if 
$\phi_{2}^{\prime}(1)<1 \Leftrightarrow \tau<(1-\gamma) / \mu w$ or $\phi_{3}^{\prime}(1)<1 \Leftrightarrow \tau<(w-1) / w(1-\mu)$. If both of them fail to hold, thesteady-state equilibrium with $u=1$.

Q.E.D.

The areas marked by $\left(\mathrm{L}^{\mathrm{S}}\right)$ and $\left(\mathrm{L}^{\mathrm{U}}\right)$ in Figure 4 indicate the sets of parameters $(w, \tau)$ satisfying the conditions for the existence of stable and unstable steady states with $u=1$, respectively. From the figure, we can find that the economy with the higher wage inequality is less likely to attain the stable steady-state equilibrium with $u=1$ and thus is more likely to avoid the poverty trap. This is because, given the redistributive tax rate, a higher wage inequality implies a larger transfer from the rich to the poor, which enables the poor to invest more in education.

\subsection{Dynamic characterization of the equilibrium}

Based on the results established so far, this subsection characterizes the motion of the distribution $u_{t}$ over time, and demonstrates the number of stable steady-state equilibria in the economy. The results established so far lead to the following dynamic characterization of the equilibrium.

Proposition 1. The equilibrium is characterized by the following properties with regard to the existence of a stable steady-state equilibrium.

(a) There are multiple, stable steady-state equilibria with $u=\bar{u}_{1}$ and $u=1$ if $\tau \geq(1-\gamma(1-\mu)) / \mu$ w and $\tau>(w-1) /(1-\mu) w ;$

(b) There are multiple, stable steady-state equilibria with $u=\bar{u}_{2}$ and $u=1$ if $\tau \in((w-1) /(1-\mu) w,(1-$ $\gamma(1-\mu)) / \mu w)$ and $w>(1-\gamma) / \mu+\gamma$

(c) There exists a unique, stable steady-state equilibrium with $u=\bar{u}_{1}$ if $\tau \in[(1-\gamma(1-\mu)) / \mu w,(w-$ 1)/(1- $\mu) w]$

(d) There exists a unique, stable steady-state equilibrium with $u=\bar{u}_{2}$ if $\tau \in((1-\gamma) / \mu w,(w-1) /(1-\mu) w]$ and $\tau<(1-\gamma(1-\mu)) / \mu w$

(e) There exists a unique, stable steady-state equilibrium with $u=1$ if $\tau<(1-\gamma) / \mu w$.

Proof. The result is immediate from lemmas 1-4 and Figure 4.

Q.E.D.

The area marked by $x \in\{=a, b, c, d, e\}$ in Figure 5 indicates the set of parameters $(w, \tau)$ satisfying the condition in the corresponding result of Proposition 1. The economy attains multiple, stable steady-state equilibria when the wage rate is higher than $(1-\gamma) / \mu+\gamma$ and the redistributive tax rate is higher than $(w-1) /(1-\mu) w$. The former condition implies a positive effect via redistribution, whereas the latter condition includes two opposing effects: the negative effect via the after-tax income of the rich and the positive effect via redistribution. As argued previously, the positive effect is greater (less) than the negative effect when the number of poor at the beginning of a period is below (above) a critical level. Therefore, depending on the initial number of poor $u_{0}$, the economy converges to one of the two stable steady-state equilibria.

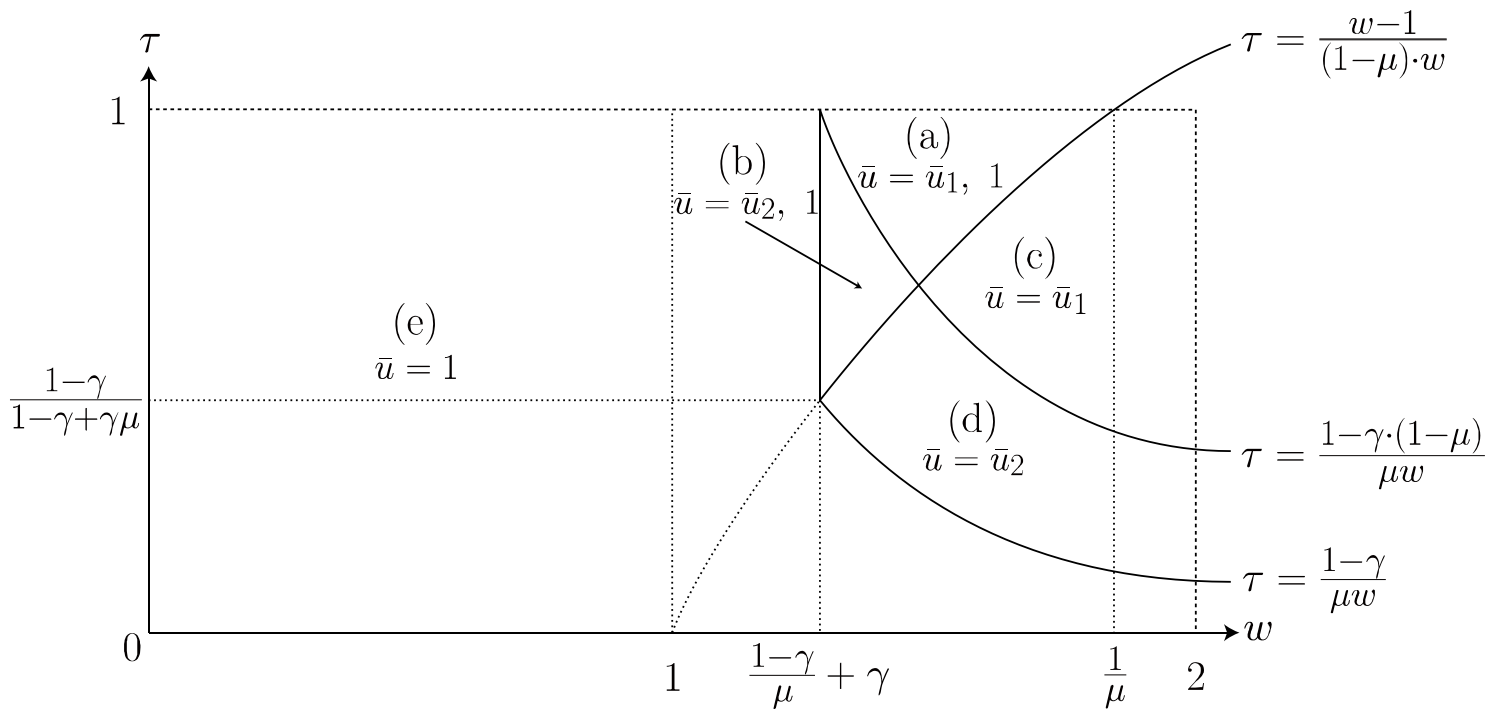

Figure 5. The set of parameters $(w, \tau)$ satisfying conditions in Proposition 1.

Figure 6 illustrates two examples of the dynamic motion of distribution $u$. Panel (a) illustrates the result of (a) in Proposition 5; i.e., the case of multiple, stable steady-state equilibria with $u=\bar{u}_{1}$ and $u=1$. When the initial 
distribution $u_{0}$ is above the critical level $\bar{u}_{3}$ the negative income effect via the after-tax income overcomes the positive effect via redistribution. The net effect of the redistributive tax is negative: the economy falls into a poverty trap in the long run. However, when the initial distribution is below $\bar{u}_{3}$, the net effect of the redistributive tax is positive: the equilibrium path converges to the steady state with $u=\bar{u}_{1}$. At this state, both the rich and the poor are financially unconstrained and can undertake their preferred level of educational investment. Panel (b) also illustrates the case of multiple, stable steady-state equilibria. However, the properties of the nontrap steady-state equilibria in panel (b) are different from those in panel (a). In the case of panel (b), the poor-born individuals suffer from the financial constraint in the long run because the redistributive tax rate in the case of panel (b) is lower than that in the case of panel (a).
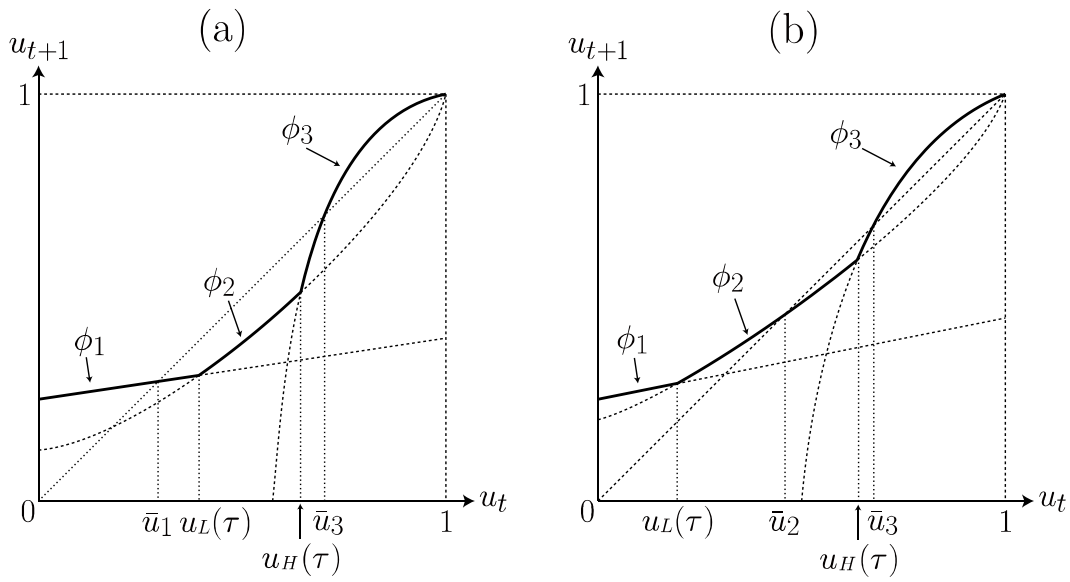

Figure 6. Examples of the dynamic motion of distribution.

The result in Proposition 1 has the following policy implication with regard to the poverty trap. Policymakers may avoid the economy falling into the poverty trap by setting a high redistributive tax rate. To confirm this argument, suppose that the wage rate is given within the range $((1-\gamma) / \mu+\gamma, \min (1 / \mu, 2))$. When the redistributive tax rate is below $(1-\gamma) / \mu w$, the economy definitely falls into the poverty trap. However, when the redistributive tax rate is set above $(1-\gamma) / \mu w$, the stable steady-state equilibrium with $u=\bar{u}_{2}$ emerges: the economy can avoid falling into the poverty trap and converges in a stable manner to the equilibrium with $u=\bar{u}_{2}$, as long as $u_{0}<1$. By raising the tax rate further, the steady-state equilibrium shifts from $u=\bar{u}_{2}$ to $u=\bar{u}_{1}$ where both the rich and the poor are financially unconstrained. The economy can move to the unconstrained equilibrium.

\section{Inequality, Mobility and Welfare}

Based on the characterization of the equilibrium in the previous section, this section considers the following questions. How does redistributive taxation affect inequality in terms of the after-tax-and-transfer income, intergenerational mobility, and welfare of individuals in each steady-state equilibrium? Which type of equilibrium is superior from the viewpoint of equality, mobility and welfare? Does a tax-induced shift of the economy from the financially constrained equilibrium to the financially unconstrained equilibrium improve equality and welfare and enhance intergenerational mobility?

To consider these issues, Subsection 4.1 introduces the Gini index measured in terms of the after-tax-and-transfer income and considers how inequality is affected by redistributive taxation. Subsection 4.2 introduces the definition of intergenerational mobility and examines the effect of redistributive taxation on mobility. Subsection 4.3 focuses on the utility of each type of the old and examines the welfare implications of a tax-induced shift between equilibria.

In what follows, we omit the poverty trap with $u=1$ from the analysis and focus on nontrivial steady-state equilibria $\left(u=\bar{u}_{1}\right.$ and $\bar{u}_{2}$ ). This is because one of our purposes here is to consider the transition from the financially constrained equilibrium to the financially unconstrained equilibrium. It is immediately found that the poverty trap involves the worst performance: the Gini coefficient is one, mobility level is zero, and the utility of the old is $-\infty$.

\subsection{Inequality}

We calculate the Gini coefficient in terms of the after-tax-and-transfer income. In particular, we focus exclusively on the Gini coefficient of the old because the young make no economic decisions in the current framework and the income level of the rich (poor) young is equivalent to that of the rich (poor) old. Panel (a) of Figure 7 summarizes information about per capita income, the number of rich and poor old, and the total income of the rich and poor old. Based on this information, we can illustrate an example of the Lorenz curve (see panel (b) of Figure 7) and calculate the 
corresponding Gini coefficient. The Gini coefficient is calculated by $A /(A+B)$ where $A$ is the shaded area and $B \equiv B 1+B 2+B 3$ in Panel (b).

Direct calculation leads to:

$$
\text { Gini }=\frac{u_{t}}{1+\frac{s_{t}}{\left(1-u_{t}\right) w(1-\tau)}},
$$

where the numerator indicates the number of poor $u_{t}$, and the denominator indicates the size of the redistribution (i.e., income of the poor) $s_{t}$, divided by the aggregate labor income of the rich, $\left(1-u_{t}\right) w(1-\tau)$. (The detail of the calculation is provided in the Appendix.) A larger value of the numerator implies a larger number of poor, thereby resulting in a higher Gini coefficient. In contrast, a larger value of the denominator implies falling income inequality between the rich and the poor, thereby resulting in a lower Gini coefficient.

In the steady-state equilibrium with $u=\bar{u}_{i}(i=1,2), \bar{u}_{\mathrm{i}}$ and $\bar{s}_{\mathrm{i}}$ are given in lemma $i(=1,2)$. Substitution of $\bar{u}_{\mathrm{i}}$ and $\overline{s_{i}}$ into Eq. (17) leads to:

$$
\text { Gini }=\left\{\begin{array}{ll}
\text { Gini }\left.\right|_{u=\bar{u}_{1}} \equiv(1-\tau) \frac{1-\gamma}{1-\gamma(1-\mu)} & \text { if } u=\bar{u}_{1} \\
\text { Gini }\left.\right|_{u=\bar{u}_{2}} \equiv(1-\tau) \frac{1-\gamma}{\mu w \tau} & \text { if } u=\bar{u}_{2}
\end{array},\right.
$$

(a)

\begin{tabular}{cccc}
\hline & the size & per capita income & total income \\
\hline rich & $1-u_{t}$ & $w(1-\tau)+s_{t}$ & $\left(1-u_{t}\right)\left\{w(1-\tau)+s_{t}\right\}$ \\
poor & $u_{t}$ & $s_{t}$ & $u_{t} s_{t}$ \\
\hline
\end{tabular}

(b)

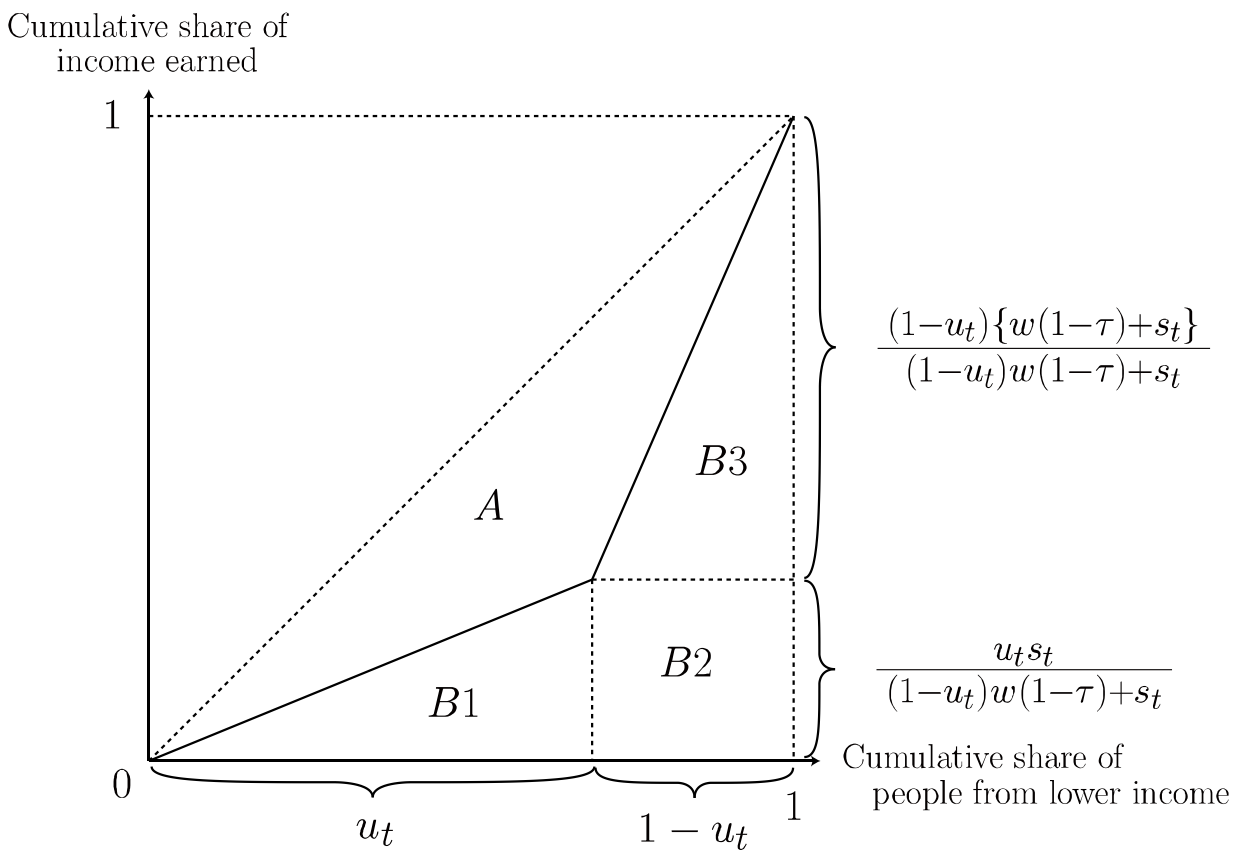

Figure 7. Panel (a) summarizes the information about the size of population, per capita income, and total income. Panel (b) illustrates the Lorenz curve.

Given this, we immediately obtain the following result with regard to the effect of redistributive taxation on inequality.

Proposition 2. A higher redistributive tax rate leads to lower steady-state inequality in terms of the 
after-tax-and-transfer income.

Redistributive taxation affects the Gini coefficient through two factors: the after-tax wage income of the rich $(1-\tau) w$ and the number of poor $u$. The former factor is represented by the term $(1-\tau)$ whereas the latter factor is represented by the term $\mu w \tau$ in Eq. (18). The latter factor does not work in the financially unconstrained equilibrium $\left(u=\bar{u}_{1}\right)$ because raising the redistributive tax rate increases the size of the redistribution, but does not affect the educational investments of the rich and the poor: both of them can choose their preferred level of educational investments in a financially unconstrained situation. In contrast, the factor represented by the number of poor does work in the financially constrained equilibrium $\left(u=\bar{u}_{2}\right)$ because the educational investment of the poor is now affected by redistribution.

When the economy is initially in a stable steady-state equilibrium with $u=\bar{u}_{2}$, an increase in the tax rate results in a lower inequality. A further increase in the tax rate would shift the economy from the equilibrium with $u=\bar{u}_{2}$ to the equilibrium with $u=\bar{u}_{1}$. This shift results in a further decrease in inequality because Gini $\left.\right|_{u=\bar{u}_{1}}<\left.\operatorname{Gini}\right|_{u=\bar{u}_{2}}$ holds. Therefore, the model shows a negative correlation between the redistributive tax and inequality, which is consistent with the empirical evidence among OECD countries.

\subsection{Intergenerational mobility}

Let $M_{t}^{u p}$ denote the number of poor-born individuals who become rich (skilled) because of educational success, and let $M_{t}^{\text {down }}$ denote the number of rich-born individuals who become poor (unskilled) because of educational failure. Under this definition, $M_{t}^{u p}$ and $M_{t}^{\text {down }}$ are given by, respectively:

$$
M_{t}^{u p} \equiv u_{t} e_{t}^{\text {poor }} ; M_{t}^{\text {down }} \equiv\left(1-u_{t}\right)\left(1-e_{t}^{\text {rich }}\right) .
$$

Because the number in each generation is unity, $M_{t}^{u p}\left(M_{t}^{\text {down }}\right)$ also denotes the proportion of the poor-born (rich-born) individuals who become rich (poor) within a generation. In the steady-state equilibrium, $\bar{M}=M^{u p}=M^{\text {down }}$ where $\bar{M}$ denotes the steady-state mobility, which we focus on below.

In the steady-state equilibrium with $u=\bar{u}_{i}(i=1,2), \bar{u}_{\mathrm{i}}$ and $\bar{s}_{\mathrm{i}}$ are given in lemmas 1 and 2. Substitution of $\bar{u}_{\mathrm{i}}$ and $\bar{s}_{\mathrm{i}}$ into Eq. (19) leads to:

$$
\bar{M}=\left\{\begin{array}{ll}
\left.\bar{M}\right|_{u=\bar{u}_{1}} \equiv \frac{(1-\gamma) \gamma \mu}{1-\gamma(1-\mu)} & \text { if } u=\bar{u}_{1} \\
\left.\bar{M}\right|_{u=\bar{u}_{2}} \equiv\left(1-\frac{1-\gamma}{\mu w \tau}\right)(1-\gamma) & \text { if } u=\bar{u}_{2}
\end{array},\right.
$$

Given this, we immediately obtain the following result with regard to the effect of redistribution on intergenerational mobility.

Proposition 3. A higher redistributive tax rate (a) has no effect on mobility in the financially unconstrained equilibrium with $u=\bar{u}_{1}$ and (b) leads to a higher mobility level in the financially constrained equilibrium with $u=\bar{u}_{2}$.

The result in proposition 3 implies a nonnegative correlation between mobility and the redistributive tax rate. To understand this implication, suppose that the economy attains the financially constrained steady-state equilibrium with $u=\bar{u}_{2}$. In this equilibrium, a higher redistributive tax rate leads to a larger redistribution, thereby resulting in a higher probability of success for the poor-born individuals (see Eq. (4)) and thus a higher mobility level. A further increase in the tax rate would shift the economy from the financially constrained equilibrium with $u=\bar{u}_{2}$ to the financially unconstrained equilibrium with $u=\bar{u}_{1}$. In the latter equilibrium, the probability of success for the poor-born individuals and that for the rich-born individuals become $\gamma$ and $\gamma \mu$, respectively, both of which are independent of the redistributive tax rate.

The key to the nonnegative correlation is financial constraints. Although the utility maximizing level of educational investment is $\gamma \mu$ for the poor old, they cannot undertake such a high level of investment when their income is below $\gamma \mu$. Their investment is limited up to their after-tax-and-transfer income, that is, the size of the redistribution, $s$, thereby resulting in a mobility level that depends on redistributive taxation. If they were allowed to borrow, they could realize their preferred level of $\gamma \mu$; the mobility level would be independent of the redistributive taxation.

The results in propositions 2 and 3 have the following prediction for inequality and mobility. Proposition 2 implies a negative correlation between redistributive tax and inequality, and proposition 3 implies a positive correlation between redistributive tax and mobility in the financially constrained equilibrium. Therefore, the model predicts that a country with a higher redistributive tax rate is characterized by lower inequality and a higher mobility level when poor 
individuals are financially constrained.

This prediction is consistent with the empirical finding that Nordic countries are characterized by high redistributive tax rates, low inequality and high mobility, while Italy, the United Kingdom and the United States are characterized by low redistributive tax rates, high inequality and low mobility. Although the model economy analyzed in this paper is abstract, the finance-constrained equilibrium provides one possible explanation for the cross-country difference in inequality and mobility affected by redistributive taxation.

The empirical evidence generally shows a negative correlation between inequality and mobility among OECD countries, as mentioned above. However, Checchi, Ichino and Rustichini (1999) report that when the focus is on a group of countries with low mobility and high inequality, the negative correlation between inequality and mobility does not necessarily hold: Italy, compared with the United States, displays less income inequality and less intergenerational mobility. This puzzling result cannot only be explained in terms of redistributive taxation, but can also be explained when the difference in wage inequality is taken into account in the following way.

Let $\tau^{j}$ and $w^{j}$ denote the redistributive tax rate and the wage of the skilled in country $j$, where $j$ denotes Italy or the US. Suppose that both countries attain an equilibrium with $u=\bar{u}_{2}$ where only the poor are financially constrained. We assume that $w^{\text {Italy }} / w^{U S}<1$, implying that wage inequality is higher in the United States than in Italy (Blau and Kahn, 1996); and assume that $\tau^{U S} / \tau^{\text {Italy }}<1$, implying that the tax rate is lower in the United States than in Italy (OECD, 2006). Under these assumptions, the Gini coefficients and mobility levels of both countries are compared as follows:

$$
\begin{gathered}
\text { Gini }\left.\right|_{u=\bar{u}_{2}} ^{U S}>\text { Gini }\left.\right|_{u=\bar{u}_{2}} ^{\text {Italy }} \Leftrightarrow \frac{w^{\text {Italy }}}{w^{U S}}>\frac{\tau^{U S}}{\tau^{\text {Italy }}} \cdot \frac{1-\tau^{\text {Italy }}}{1-\tau^{U S}}, \\
\left.\bar{M}\right|_{u=\bar{u}_{2}} ^{U S}>\left.\bar{M}\right|_{u=\bar{u}_{2}} ^{\text {Italy }} \Leftrightarrow \frac{w^{\text {Italy }}}{w^{U S}}<\frac{\tau^{U S}}{\tau^{\text {Italy }} .}
\end{gathered}
$$

Figure 8 illustrates these two conditions in the $\tau^{U S} / \tau^{\text {Italy }}-w^{\text {Italy }} / w^{U S}$ space. When the ratios $\tau^{U S} / \tau^{\text {Italy }}$ and $w^{\text {Italy }} / w^{U S}$ are given to satisfy the shaded area in Figure 7, Italy displays less mobility and less inequality compared with the United States. Our analysis suggests that wage inequality as well as redistributive taxation are the keys to explaining the difference in inequality and mobility between Italy and the United States.

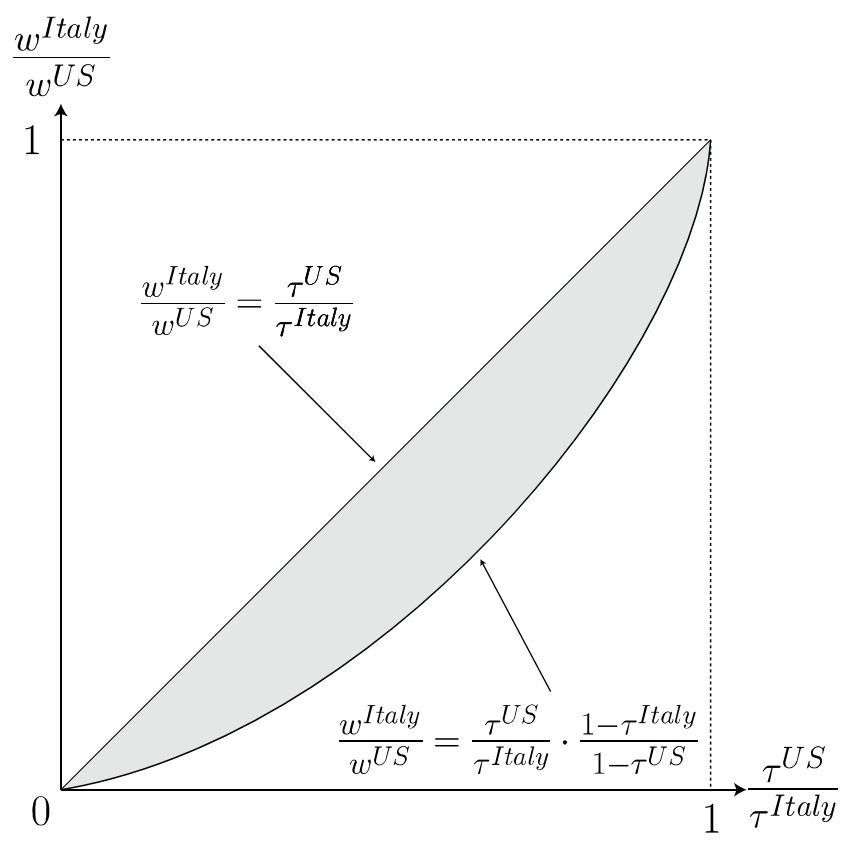

Figure 8 . The shaded area illustrates the case where Italy is less mobile and less unequal compared to the United States. 4.3 Welfare Analysis

The analysis in the previous two subsections shows that raising the redistributive tax rate is desirable from the viewpoint of equality and mobility in the economy. In this subsection, we take a further step and examine the welfare implications of redistributive taxation. In particular, we consider whether raising the redistributive tax rate improves the utility of each type of individual and thus attains a Pareto improvement. 
For the purpose of analysis, we focus on the steady-state indirect utility functions of the rich old and the poor old, $\bar{V}^{\text {old,rich }}$ and $\bar{V}^{\text {old,poor }}$, calculated as follows:

$$
\begin{gathered}
\bar{V}^{\text {old,rich }}= \begin{cases}\left.\bar{V}^{\text {old,rich }}\right|_{u=\bar{u}_{1}} \equiv w(1-\tau)+\frac{\gamma \mu}{1-\gamma(1-\mu)} w \tau+\gamma \log \gamma-\gamma & \text { if } u=\bar{u}_{1}, \\
\left.\bar{V}^{\text {old,rich }}\right|_{u=\bar{u}_{2}} \equiv w+\gamma \log \gamma-\gamma & \text { if } u=\bar{u}_{2}\end{cases} \\
\bar{V}^{\text {old,poor }}= \begin{cases}\left.\bar{V}^{\text {old,poor }}\right|_{u=\bar{u}_{1}} \equiv \frac{\gamma \mu}{1-\gamma(1-\mu)} w \tau+\gamma \log \gamma \mu-\gamma & \text { if } u=\bar{u}_{1} \\
\left.\bar{V}^{\text {old,poor }}\right|_{u=\bar{u}_{2}} \equiv \gamma \log \mu\left(w \tau-\frac{1-\gamma}{\mu}\right) & \text { if } u=\bar{u}_{2}\end{cases}
\end{gathered}
$$

Given this, we immediately obtain the following result.

Proposition 4. Raising the redistributive tax rate (a) decreases the utility of the rich old and improves the utility of the poor old in the financially unconstrained equilibrium with $u=\bar{u}_{1}$ and (b) has no effect on the utility of the rich old but improves the utility of the poor old in the financially constrained equilibrium with $u=\bar{u}_{2}$.

The result in proposition 4 indicates that in the steady-state equilibrium with $u=\bar{u}_{1}$, the utility of the rich old is decreasing in $\tau$ whereas the utility of the poor old is increasing in $\tau$. In contrast, in the steady-state equilibrium with $u=\bar{u}_{2}$, the utility of the rich old is independent of $\tau$ whereas the utility of the poor old is increasing in $\tau$. In other words, there is a conflict between rich and poor in the financially unconstrained equilibrium, while there is no such conflict in the financially constrained equilibrium.

The difference between the two cases comes from the financial constraints of the poor. In the financially unconstrained equilibrium, a marginal increase in the tax rate has no effect on the levels of educational investment for the rich and the poor because their investment levels are given by $e^{r i c h}=\gamma$ and $e^{\text {poor }}=\gamma \mu$. A higher tax rate decreases the consumption of the rich and increases the consumption of the poor, thereby creating a trade-off between the consumption of these two groups.

In contrast, in the financially constrained equilibrium with $u=\bar{u}_{2}$, such a trade-off no longer exists. To see this, rewrite the utility functions of the rich old and poor old as:

$$
\begin{gathered}
\left.\bar{V}^{\text {old,rich }}\right|_{u=\bar{u}_{2}}=w(1-\tau)+\left(w \tau-\frac{1-\gamma}{\mu}\right)+\gamma \log \gamma-\gamma, \\
\left.\bar{V}^{\text {old,poor }}\right|_{u=\bar{u}_{2}}=\bar{s}^{2}+\gamma \log \mu \bar{s}^{2}-\frac{1}{\mu} \times \mu \bar{s}^{2} .
\end{gathered}
$$

For the rich, an increase of the tax burden is offset completely by an increase of the transfer: a marginal change of the tax rate has no effect on the utility of the rich. For the poor, an increase in the tax rate is equivalent to an increase of resources available for educational investment, which results in an improvement of utility from education.

The result in proposition 4 implies that raising the tax rate leads to a Pareto improvement in terms of the utility of the old when the economy is initially in the financially constrained equilibrium with $u=\bar{u}_{2}$. However, a further increase may fail to attain an improvement once the economy shifts to the financially unconstrained equilibrium. Therefore, with the results in propositions 2 and 3, we can conclude that raising the redistributive tax rate is beneficial in terms of equality, mobility and welfare as long as the economy stays in the financially constrained equilibrium, but is not desirable from the viewpoint of the utility of the rich old when the economy attains the financially unconstrained equilibrium.

\section{Concluding remarks}

This paper presented a simple theoretical model that analyzes the joint determination of income inequality and intergenerational mobility affected by redistributive taxation. Raising the redistributive tax rate relaxes the financial constraints of the poor. This enhances the educational investment of the poor, thereby resulting in a larger number of poor-born individuals who can become rich. Therefore, a higher tax rate leads to a lower inequality and a higher mobility in the economy when the poor are financially constrained.

A further increase in the tax rate shifts the economy to the financially unconstrained equilibrium. In this new equilibrium, raising the tax rate implies a simple income transfer from the rich to the poor, thereby creating a trade-off between the rich and the poor in terms of consumption, i.e., utility. Therefore, the model implies that raising the tax rate is beneficial from the viewpoint of equality and mobility, but is not necessarily beneficial from the viewpoint of utility. 
The current framework is used to provide a potential explanation for the cross-country differences in inequality and mobility among OECD countries. Empirical studies show that a country with a higher redistributive tax rate is characterized by lower inequality and higher mobility. In addition, within a group of low-mobility and high-inequality countries including Italy and the United States, there is a puzzling result that Italy, compared with the United States, displays less mobility and less inequality. Our paper gives a simple explanation for these empirical findings by focusing on the size of the redistribution as well as wage inequality.

It should be noted that there are at least two caveats to the analysis. First, for the simplicity of analysis, the wage of the poor is assumed to be zero. When the assumption is changed to the poor receiving some positive wages, tax revenues arise from the poor. In the poverty trap where all parents are poor, some poor-born individuals can become rich because poor parents can finance some amount of educational investment by themselves. However, multiple steady-state equilibria are expected to remain under this extended framework.

Second, the wage of the rich is assumed to be fixed. When the assumption is changed so that the wages of the rich and poor are endogenous such that each of them receives his/her marginal product of labor, the framework can be utilized to analyze the joint determination of wage inequality and mobility, but at the cost of losing simplicity. Although these extensions are expected to provide additional insights, we leave them for future work.

\section{Acknowledgements}

The authors would like to thank two anonymous referees for their valuable comments and suggestions.

\section{References}

Banerjee, A. V., \& Newman, A. F. (1993). Occupational choice and the process of development. Journal of Political Economy, 101, 274-298.

Becker, G. S., \& Tomes, N. (1979). An equilibrium theory of the distribution of income and intergenerational mobility. Journal of Political Economy, 87, 1153-1189.

Blau, F. D., \& Kahn, L. M. (1996). International differences in male wage inequality: institutions versus market forces. Journal of Political Economy, 104, 791-836.

Blumkin, T., \& Sadka, E. (2005). Income taxation with intergenerational mobility: Can higher inequality lead to less progression? European Economic Review, 49, 1915-1925.

Checchi, D., Ichino, A., \& Rustichini, A. (1999). More equal but less mobile? Education financing and intergenerational mobility in Italy and in the US. Journal of Public Economics, 74, 351-393.

D'Addio, A. C. (2007). Intergenerational transmission of disadvantage: mobility or immobility across generations? A review of the evidence for OECD countries. OECD social, employment and migration working papers 52, Paris: OECD.

Davies, J. B., Zhang, J., \& Zeng, J. (2005). Intergenerational mobility under private vs. public education. Scandinavian Journal of Economics, 107, 399-417.

Freeman, S. (1996). Equilibrium income inequality among identical agents. Journal of Political Economy, 104, 1047-1064.

Galor, O., \& Zeria, J. (1993). Income distribution and macroeconomics. Review of Economic Studies, 60, 35-52.

Ghatak, M., \& Jiang, N. N-H. (2002). A simple model of inequality, occupational choice, and development. Journal of Development Economics, 69, 205-226.

Hassler, J., Rodriguez Mora, J. V., \& Zeira, J. (2007). Inequality and mobility. Journal of Economic Growth, 12, 235-259.

Ichino, A., Karabarbounis, L., \& Moretti, E. (2008). The political economy of intergenerational income mobility. http://www.parisschoolofeconomics.eu/IMG/pdf/Ichino.pdf

Iyigun, M. F. (1999). Public education and intergenerational economic mobility. International Economic Review, 40, 697-710.

Ljungqvist, L. (1993). Economic underdevelopment: the case of missing market for human capital. Journal of Development Economics, 40, 219-239.

Maoz, Y. D., \& Moav, O. (1999). Intergenerational mobility and the process of development. Economic Journal, 109, 677-697.

Mookherjee, D., \& Napel, S. (2007). Intergenerational mobility and macroeconomic history dependence. Journal of Economic Theory, 137, 49-78. 
Mookherjee, D., \& Ray, D. (2003). Persistent inequality. Review of Economic Studies, 70, 369-393.

Napel, S., \& Schneider, A. (2008). Intergenerational talent transmission, inequality, and social mobility. Economics Letters, 99, 405-409.

OECD. (2006). Society at a Glance: OECD SocialIndicators 2006 Edition, Paris, OECD.

Owen, A. L., \& Weil, D. N. (1998). Intergenerational earnings mobility, inequality and growth. Journal of Monetary Economics, 41, 71-104.

Piketty, T. (2000). Theories of persistent inequality and intergenerational mobility. In: Atkinson, A.B., Bourguignon, F. (eds), Handbook of Income Distribution, Amsterdam: North-Holland, 429-476.

Solon, G. (2004). A model of intergenerational mobility variation over time and place. In Corak, M. (ed.), Generational Income Mobility in North America and Europe, Cambridge: Cambridge University Press, 38-47.

\section{Notes}

Note 1 . The size of rich agents in period $t$ is $\left(1-u_{t}\right) \cdot e_{t}^{r i c h}+u_{t} \cdot e_{t}^{\text {poor }}+\left(1-u_{t}\right)$. Since each agents has a unit mass, the government budget constraint in period $t$ is $2 s_{t}=\left\{\left(1-u_{t}\right) \cdot e_{t}^{\text {rich }}+u_{t} \cdot e_{t}^{\text {poor }}+\left(1-u_{t}\right)\right\} \cdot w \tau$.

Note 2. Note that the degree of educational concern may be different between the rich and the poor papents. Since our concern in this paper is to investigate the joint determination of income inequality and intergenerational mobility under a finance-constrained economy, we assume that $\gamma$ is identical for the rich and the poor.

\section{Appendix A}

Derivation of Eq. (17)

The Gini coefficient is calculated by $\operatorname{Gini}=A /(A+B)$, or:

$$
\begin{aligned}
\text { Gini } & =1-\frac{B 1+B 2+B 3}{A+(B 1+B 2+B 3)} \\
& =1-2(B 1+B 2+B 3)
\end{aligned}
$$

where the second line comes from $A+(B 1+B 2+B 3)=1 / 2$. Given that:

$$
\begin{aligned}
& B 1=\frac{1}{2} u_{t} \frac{u_{t} s_{t}}{\left(1-u_{t}\right) w(1-\tau)+s_{t}}, \\
& B 2=\left(1-u_{t}\right) \frac{u_{t} s_{t}}{\left(1-u_{t}\right) w(1-\tau)+s_{t}}, \\
& B 3=\frac{1}{2}\left(1-u_{t}\right) \frac{\left(1-u_{t}\right)\left\{w(1-\tau)+s_{t}\right\}}{\left(1-u_{t}\right) w(1-\tau)+s_{t}},
\end{aligned}
$$

we obtain:

$$
2(B 1+B 2+B 3)=\frac{\left(u_{t}\right)^{2} s_{t}+2\left(1-u_{t}\right) u_{t} s_{t}+\left(1-u_{t}\right)^{2}\left\{w(1-\tau)+s_{t}\right\}}{\left(1-u_{t}\right) w(1-\tau)+s_{t}}
$$

Therefore, we have:

$$
\begin{aligned}
\text { Gini } & =1-\frac{\left(u_{t}\right)^{2} s_{t}+2\left(1-u_{t}\right) u_{t} s_{t}+\left(1-u_{t}\right)^{2}\left\{w(1-\tau)+s_{t}\right\}}{\left(1-u_{t}\right) w(1-\tau)+s_{t}} \\
& =\frac{\left(1-u_{t}\right) w(1-\tau) u_{t}}{\left(1-u_{t}\right) w(1-\tau)+s_{t}} \\
& =\frac{u_{t}}{1+\frac{s_{t}}{\left(1-u_{t}\right) w(1-\tau)}}
\end{aligned}
$$

\section{(cc) $\mathbf{E Y}$}

This work is licensed under a Creative Commons Attribution 3.0 License. 